\title{
Outcomes of Patients with Newly Diagnosed Cardiac Myxoma: A Retrospective Multicentric Study
}

\author{
Frantisek Nehaj, ${ }^{1}$ Juraj Sokol $\left(\mathbb{D},{ }^{2}\right.$ Michal Mokan, ${ }^{1}$ Veronika Jankovicova, ${ }^{3}$ \\ Frantisek Kovar, ${ }^{1}$ Marianna Kubaskova, ${ }^{4}$ Stanislav Mizera, ${ }^{5}$ and Marian Mokan ${ }^{1}$ \\ ${ }^{1}$ First Department of Internal Medicine, Jessenius Faculty of Medicine in Martin, Comenius University in Bratislava, Kollarova 2, \\ 03659 Martin, Slovakia \\ ${ }^{2}$ Department of Haematology and Transfusion Medicine, National Centre of Haemostasis and Thrombosis, \\ Jessenius Faculty of Medicine in Martin, Comenius University in Bratislava, Kollarova 2, 03659 Martin, Slovakia \\ ${ }^{3}$ Central Slovakian Institute for Cardiac and Vascular Diseases, Cesta K Nemocnici 622/1, 97401 Banska Bystrica, Slovakia \\ ${ }^{4}$ Department of Radiology, Jessenius Faculty of Medicine in Martin, Comenius University in Bratislava, Kollarova 2, \\ 03659 Martin, Slovakia \\ ${ }^{5}$ The National Institute of Cardiovascular Diseases, Pod Krasnou Horkou 1, 83348 Bratislava 37, Slovakia
}

Correspondence should be addressed to Juraj Sokol; juraj.sokol@me.com

Received 30 September 2017; Accepted 9 January 2018; Published 6 February 2018

Academic Editor: Dirk Bandorski

Copyright (C) 2018 Frantisek Nehaj et al. This is an open access article distributed under the Creative Commons Attribution License, which permits unrestricted use, distribution, and reproduction in any medium, provided the original work is properly cited.

The patient database at the First Department of Internal Medicine in Martin, the Central Slovak Institute for Cardiac and Vascular Diseases in Banska Bystrica, and the National Slovak Institute of Cardiovascular Diseases in Bratislava was searched to identify patients with benign tumors of the heart seen during the 5-year period between 2011 and 2016. Forty-one patients with primary cardiac myxomas were identified and their medical records were reviewed for details pertaining to presenting symptoms, staging modalities, treatment approaches, and outcomes. Most of the studied patients were diagnosed with echocardiography $(n=35$, $85 \%)$. The occurrence of the tumor was higher in the female population $(n=25,61 \%)$. The most common presenting symptoms were dyspnoea $(n=17,42 \%)$, chest pain $(n=3,7 \%)$, or pain and paraesthesia of the limbs $(n=2,5 \%)$. Acute embolic event due to embolization of tumor fragments resulted in cerebral stroke $(n=5,12 \%)$. All patients were treated by resection. Only one comorbid patient died due to multiple-organ dysfunction syndrome two weeks after the resection. The most common postoperative complication was bleeding $(n=2,5 \%)$ and infection $(n=2,5 \%)$. The early diagnosis and appropriate treatment are often curative, with very low risk of recurrence. Postoperative survival is high.

\section{Introduction}

First recognition of a heart tumor is attributed to Columbus in 1559 [1], followed by Malpighi, who in 1666 wrote a dissertation entitled "De polypo cordis" [2]. Bahnson and Newman (1953) reported the earliest surgical approaches to myxomas by removing a myxoma from the right atrium via right anterior thoracotomy using a short period of caval obstruction at normothermia. Crafoord (1955) successfully excised a myxoma from left atrium using cardiopulmonary bypass [3]. Coates and Drake (1958) reported a successful excision of a right atrial myxoma [4]. Patients with a heart tumor have a wide range of symptoms. General symptoms include exhaustion, dyspnoea, syncope, and chest pain. They could cause symptoms by three mechanisms: intracardiac obstruction, systematic embolization of tumor fragments, or constitutional symptoms by unclear mechanisms [5]. Obstruction may restrict the blood flow into the heart, mimicking stenosis of the mitral or tricuspid valve. Malignant tumors are often manifested with weight loss, fever, night sweating, or haemorrhagic pericardial effusion. Malignant tumors that metastasize to the heart are nearly 50 times more common than tumors originating from the heart [6]. Tumors that originate from the heart are benign in approximately $75 \%$ and nearly $50 \%$ of these are myxomas [7]. Other types of primary benign tumors of the heart include lipomas, 
fibromas, haemangiomas, teratomas, and rhabdomyomas. The frequency of primary cardiac tumors is approximately $0.02 \%$, corresponding to 200 tumors in 1 million autopsies, based on the data of 22 large autopsy series [8-11]. Myxomas most commonly arise from left atrium, usually from a stalk attached to the atrial septum, 75\% in the left atrium, up to $20 \%$ in the right atrium, and around $8 \%$ in the ventricles. Peripheral embolization occurs in up to $30 \%$ of cases and most of them embolize to the central nervous system [12]. Because of the very rare occurrence of primary cardiac tumors, there are only few case series in the literature describing the epidemiology, presentation, and outcome of cardiac myxomas. The purpose of this retrospective study is to define and describe the characteristic, behaviour, and prognostic indicators of cardiac myxomas on a large group of patients.

\section{Methods}

Three cardiovascular centres participated in this study: the First Department of Internal Medicine in Martin, the Central Slovak Institute for Cardiac and Vascular Diseases in Banska Bystrica, and the National Slovak Institute of Cardiovascular Diseases in Bratislava. The patient-related data were obtained from medical records. Between 2011 and 2016, 41 patients were diagnosed with primary cardiac tumor. All tumors were benign known as myxomas, 39 were in left atrium (95\%), and 2 were in the right atrium (5\%). These patients were treated with surgical resection, which is associated with excellent long-term survival. We did not observed recurrence in the presented group of patients. Statistical Package for the Social Sciences (SPSS, Inc., Chicago, Illinois, USA) was used for analysis. Statistical analysis consisted of basic descriptive statistics. Kaplan-Meier curves were constructed to estimate the cumulative survival.

\section{Results}

The most common presenting symptoms were dyspnoea $(n=$ $17,42 \%)$, chest pain $(n=3,7 \%)$, or pain and paraesthesia of the limbs $(n=2,5 \%)$. Nonspecific symptoms such as weight loss or fever were uncommon. Acute embolic event as a first sign of cardiac myxoma occurred in eight patients $(20 \%)$. Cerebral stroke was the most frequent $(n=5,12 \%)$. Some of the cases of cardiac myxoma were diagnosed accidentally $(n=4,10 \%)$. The majority of the patients were diagnosed by echocardiography $(n=35,85 \%)$. Other useful diagnostic methods were computed tomography $(n=5,12.5 \%)$ or histology $(n=1,2.5 \%)$.

More than half of the patients had no valvular heart disease $(n=21,51 \%)$. The most common valvular heart disease not caused by heart tumor was aortic stenosis $(n=$ $8,20 \%)$. Mitral stenosis, secondary to tumor prolapse, was relatively common in patients with left atrial myxoma. There was a higher incidence of mitral regurgitation in patients with left atrial tumors. The patients with the right atrial myxoma had no valvular disease. Pulmonary hypertension was diagnosed in $51 \%$ of the patients $(n=21)$, mostly due to pulmonary diseases. Cardiac myxomas varied in size, the mean height was $3.27 \pm 1.57 \mathrm{~cm}$, and the mean
TABLE 1: General characteristics and diagnostic method of cardiac myxoma.

\begin{tabular}{lc}
\hline General characteristic & $\begin{array}{c}\text { Number of } \\
\text { patients or } \\
\text { values }\end{array}$ \\
\hline $\begin{array}{l}\text { Mean age at the time of surgery, years } \pm \text { SD } \\
\text { (range) }\end{array}$ & $\begin{array}{c}61.78 \pm 7.87 \\
(48-81)\end{array}$ \\
(i) $>65$ years & 12 \\
(ii) $<65$ years & 29 \\
Sex & \\
(i) Male & 16 \\
(ii) Female & 25 \\
BMI (kg/m2) & 13 \\
(i) Normal weight (18.5-24.9) & 16 \\
(ii) Overweight (25.0-29.9) & 12 \\
(iii) Obese (30.0-39.9) & \\
Location & 39 \\
(i) Left atrium & 2 \\
(ii) Right atrium & \\
Size of tumor & $3.27 \pm 1.57$ \\
(i) Tumor mean height in cm, $\pm S D$ (range) & $(0.90-7.50)$ \\
(ii) Tumor mean length in cm, $\pm S D$ (range) & $2.91 \pm 0.91$ \\
Carney complex & $1.20-5.00)$ \\
Diagnostic method & 0 \\
(i) Echocardiography & \\
(ii) Computed tomography & \\
(iii) Histology & \\
\hline
\end{tabular}

length was $2.91 \pm 0.91 \mathrm{~cm}$. General characteristics and the diagnostic method of cardiac myxoma are shown in Table 1 and all echocardiographic and hemodynamic characteristics are shown in Table 3.

Despite tumor mass inside the left atrium of the heart, the systolic function remained good. The ejection fraction of the left ventricle, which was less than $50 \%$, was present in $29 \%$ cases $(n=12)$. According to functional classification known as New York Heart association (NYHA), approximately $80 \%$ $(n=33)$ of patients presented in NYHA II/III. The presenting and other characteristics of cardiac myxoma are shown in Table 2 .

Cardiovascular risk factors included diabetes mellitus in $44 \%(n=18)$, cerebral stroke history in $20 \%(n=8)$, hypertension in $85 \%(n=35)$, and smoking in $22 \%(n=9)$. The coronary artery disease (CAD) was present in 15 patients $(37 \%)$. All the patients with triple-vessel disease $(n=7,17 \%)$ were treated by coronary artery bypass grafting (CABG). Patients with single and double vessel disease underwent coronary angioplasty (20\%).

The occurrence of the tumor was higher in a female population $(n=25,61 \%)$, than in male population $(n=16$, $39 \%)$. There was no significant difference in the occurrence of a heart tumor based on body weight. Approximately $7 \%$ of all 
TABLE 2: Presenting and other characteristics of cardiac myxoma.

\begin{tabular}{|c|c|}
\hline Presenting characteristics & $\begin{array}{c}\text { Number of patients } \\
\text { or value }\end{array}$ \\
\hline \multicolumn{2}{|l|}{ Presenting sign or symptom } \\
\hline Dyspnoea & 17 \\
\hline Chest pain & 3 \\
\hline Pain and paraesthesia of limbs & 2 \\
\hline Palpitation & 1 \\
\hline \multicolumn{2}{|l|}{ Peripheral embolism } \\
\hline (a) Cerebral stroke & 5 \\
\hline (b) Acute arterial occlusion & 2 \\
\hline (c) Acute myocardial infarction & 1 \\
\hline Atrial fibrillation & 2 \\
\hline Syncope & 1 \\
\hline Heart failure & 1 \\
\hline \multicolumn{2}{|l|}{ Nonspecific symptom } \\
\hline (a) Weight loss & 1 \\
\hline (b) Fever & 1 \\
\hline None & 4 \\
\hline \multicolumn{2}{|l|}{ Rhythm } \\
\hline (i) Sinus rhythm & 33 \\
\hline (ii) Atrial fibrillation & 8 \\
\hline \multicolumn{2}{|l|}{$\begin{array}{l}\text { Functional classification according to the } \\
\text { New York Heart Association (NYHA) }\end{array}$} \\
\hline (i) I & 6 \\
\hline (ii) II & 25 \\
\hline (iii) III & 8 \\
\hline (iv) IV & 2 \\
\hline \multicolumn{2}{|l|}{ Risk factors } \\
\hline (i) Diabetes mellitus & 18 \\
\hline (ii) Arterial hypertension & 35 \\
\hline (iii) Chronic obstructive disease of lungs & 5 \\
\hline (iv) Smoking & 9 \\
\hline Cerebral stroke history & 8 \\
\hline Coronary artery disease & 15 \\
\hline (i) Single-vessel disease & 3 \\
\hline (ii) Double-vessel disease & 5 \\
\hline (iii) Triple-vessel disease & 7 \\
\hline
\end{tabular}

cardiac myxomas are associated with Carney complex, which has an increased risk of recurrence and is a genetic disorder characterized by an increased risk of several types of tumors [13-16]. None of the patients from this study presented with Carney complex.

\section{Surgical Statistics}

None of the cardiac tumors were treated conservatively. Coronary artery bypass grafting and aortic valve repair or replacement were the most common concomitant surgical procedure. The concomitant operation was done in $27 \%$ patients $(n=11)$, from which only $7 \%(n=3)$ underwent
TABLE 3: Echocardiographic and hemodynamic characteristics of cardiac myxoma.

\begin{tabular}{lc}
\hline & $\begin{array}{c}\text { Number } \\
\text { of } \\
\text { patients } \\
\text { or } \\
\text { values }\end{array}$ \\
& \\
\hline Valvular heart disease & 4 \\
(i) Mitral regurgitation & 0 \\
(ii) Mitral stenosis & 4 \\
(iii) Aortic regurgitation & 8 \\
(iv) Aortic stenosis & 4 \\
(v) Tricuspid regurgitation & 0 \\
(vi) Pulmonary regurgitation & 21 \\
(vii) None & \\
Ejection fraction & 29 \\
(i) $\geq 50 \%$ & 10 \\
(ii) $30-49 \%$ & 2 \\
(iii) <30\% & \\
Pulmonary hypertension, mPAP, mmHg & 4 \\
(i) Severe pulmonary hypertension $>45$ mmHg & 4 \\
(ii) Moderate pulmonary hypertension $36-45 \mathrm{mmHg}$ & 8 \\
(iii) Mild pulmonary hypertension $25-35 \mathrm{mmHg}$ & 9 \\
(iv) Normal & 20 \\
Carotid arteries & \\
(i) Hemodynamically significant stenosis $\geq 60 \%$ & 0 \\
(ii) Nonhemodynamically significant stenosis $<60 \%$ & 41 \\
\hline & \\
\hline
\end{tabular}

valve procedure. The incidence of postoperative complications was $17 \%(n=7)$ and included sternal infection, pneumonia, bleeding requiring reoperation, and renal and respiratory insufficiency. The most common complication was infection $(n=2)$ and bleeding $(n=2)$. The infection occurred in both patients with diabetes. In general, the postoperative healing process is slower and the risk of infection is higher in diabetic patients. The bleeding complication with drop in haemoglobin levels $(125 \rightarrow 68 \mathrm{~g} / \mathrm{L}$ and $130 \rightarrow 65 \mathrm{~g} / \mathrm{L})$, verified as severe anaemia, was observed in 2 patients. The renal and respiratory insufficiency occurred in one comorbid patient, who died because of multiple-organ dysfunction syndrome two weeks after resection.

The surgical characteristics with extracorporeal circulation time (ECC), cross-clamp time, and temperature are shown in Table 4.

\section{Survival Analysis}

Duration of follow-up was counted from date of diagnosis to end of follow-up, defined as the date of the death or the date of last phone contact which was December 31, 2017. The median of follow-up was $221.53 \pm 107.47$ weeks (range 3-395 weeks). During follow-up, six patients died for an incidence rate 3.4 (95\% CI 1.3-7.5) per 100 person-year. One patient died two 
TABLE 4: Surgical characteristics and postoperative parameters of cardiac myxoma.

\begin{tabular}{lc}
\hline Operative parameters & \multicolumn{2}{c}{ Number of patients or values } \\
Surgical procedure (resection) & 39 \\
Concomitant operations & 2 \\
$\quad$ (i) Coronary artery bypass grafting & 8 \\
(ii) Mitral valve procedure & 1 \\
(iii) Aortic valve procedure & 2 \\
(iv) Tricuspid valve procedure & 0 \\
(v) Pulmonary valve procedure & 0 \\
Extracorporeal time, mean time in minutes \pm SD (range) & $59.61 \pm 30.917(21-152)$ \\
Cross-clamp time, mean time in minutes \pm SD (range) & $44.73 \pm 17.574(17-128)$ \\
Cardiopulmonary bypass temperature, mean in degrees of Celsius \pm SD (range) & $34.15 \pm 1.31(29.7-36.0)$ \\
Postoperative complications & 7 \\
(i) Bleeding & 2 \\
(ii) Renal insufficiency & 1 \\
(iii) Pulmonary embolism & 1 \\
(iv) Respiratory insufficiency & 1 \\
(v) Infection & 1 \\
\hline
\end{tabular}

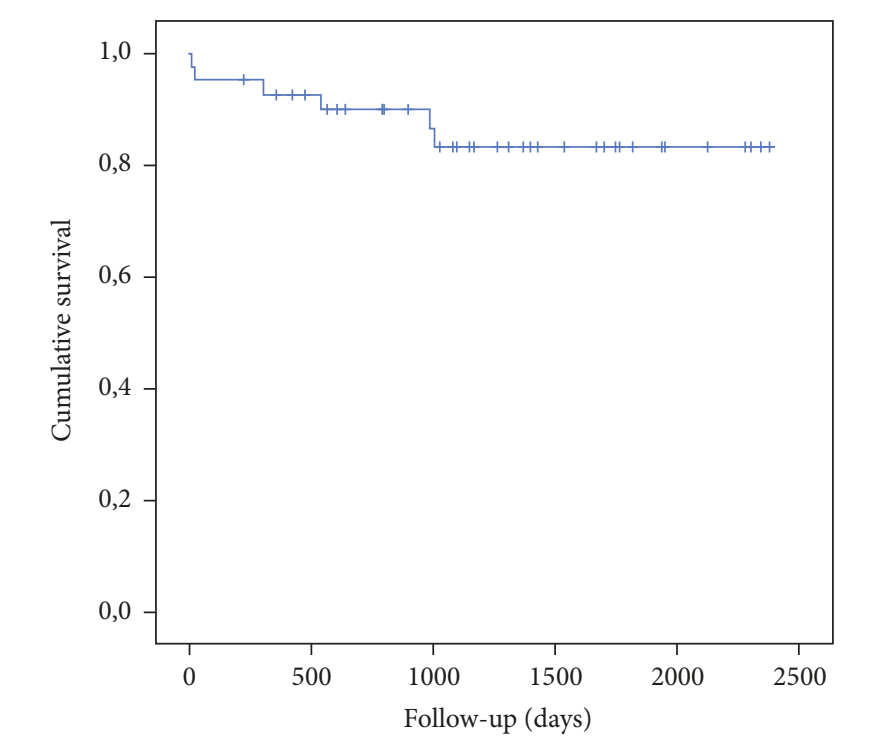

$\begin{array}{llllll}\text { Number at risk } 41 & 38 & 36 & 35 & 35 & 35\end{array}$

$\neg$ Survival function

FIGURE 1: Kaplan-Maier curve of survival.

weeks after surgery. The other five patients died for an average of 68 weeks after the resection; see Figure 1.

In this study, postoperative survival was not significantly different from age- and sex-matched individuals in the population. The mean age at tumor diagnosis was $61.78 \pm$ 7.87 years. After discharge, all patients underwent medical examination with echocardiography. None of the patients from this study had recurrence of myxoma. Surgical en bloc resection with a margin of normal tissue, if anatomically feasible, is considered curative.

\section{Discussion}

Primary cardiac tumors are uncommon; cardiac myxoma has the highest incidence. The most significant predictor of cardiac tumors is histology. To illustrate how rare malignant primary cardiac tumors are, only 34 patients were identified at the Mayo Clinic between 1975 and 2007. All of them were sarcomas, and the most common histologic type was angiosarcoma (41\%) [14]. Malignant tumors are more common in children. Cardiac myxomas occur in all age groups, most frequently in patients of ages between 40 and $60[17,18]$. Women are more often diagnosed with cardiac myxoma also in this group of patients $(n=25,61 \%)$.

In our retrospective study, all patients $(n=41)$ were treated with surgical resection. The postoperative survival was not different from age- and sex-matched individuals in the population with no recurrence of cardiac myxoma. The most common first symptom of the tumor was dyspnoea. Patients with presenting symptom such as peripheral embolism $(n=8,19.5 \%)$ or patients who were asymptomatic ( $n=4,9.75 \%)$ were younger $(53.87 \pm 5.32)$ in comparison with the mean age of our study group. The majority of the patients were diagnosed by echocardiography. The ejection fraction of the left ventricle remains relatively good in most patients. Regarding cardiac mass inside the heart, mitral stenosis was common in patients with left atrial myxoma. Postoperative survival is high. Only one comorbid patient died due to multiple-organ dysfunction syndrome two weeks after the resection. The most common postoperative complication was bleeding and infection.

\section{Conclusion}

The most common first symptom of cardiac myxoma is dyspnoea. The majority of our patients were diagnosed by echocardiography. Prompt excision using cardiopulmonary 
bypass has been established as the only acceptable mode of treatment for these tumors. The surgeon must try to prevent fragmentation and intraoperative embolization. Nevertheless, the postoperative survival is high with a very low rate of complications.

\section{Abbreviations}

CAD: Coronary artery disease

CABG: Coronary artery bypass grafting

ECC: Extracorporeal circulation time

NYHA: New York Heart Association

SPSS: Statistical Package for the Social Sciences.

\section{Conflicts of Interest}

The authors declare that they have no conflicts of interest.

\section{Authors' Contributions}

Each author made substantial contributions to the submitted work. Juraj Sokol, Marian Mokan, and Frantisek Nehaj contributed to conception and design of the study. Echocardiography study was performed by Frantisek Nehaj, Frantisek Kovar, and Marianna Kubaskova. Marian Mokan, Veronika Jankovicova, and Stanislav Mizera performed acquisition of data. Marian Mokan carried out revision of the language. Stanislav Mizera and Marian Mokan carried out analysis and interpretation of the data. Marian Mokan, Frantisek Nehaj, and Stanislav Mizera drafted the article and/or revised it critically for important intellectual information and content. Juraj Sokol edited the revised version. All authors approved the final manuscript.

\section{Acknowledgments}

The authors gratefully acknowledge the cooperation of all patients. Funding this work was supported by Grant VEGA $1 / 0187 / 17$.

\section{References}

[1] M. R. Columbus, Anatomica, Venice: N Beui, vol. 15, p. 269, 1559.

[2] M. Malpighi, De Viscerum Strudura, Cui accessit de Polypo cordis. Montii Bononiae. 1666.

[3] C. L. Crafoord, Discussion on mitral stenosis and mitral insufficiency, vol. 1, W. B. Saunders, Philadelphia, Pa, USA, 1955.

[4] E. O. Coates and E. H. Drake, "Myxoma of the right atrium, with variable right-to-left shunt; clinical and physiologic observations and report of a case with successful operative removal," The New England Journal of Medicine, vol. 259, no. 4, pp. 165$169,1958$.

[5] A. J. Larrieu, W. R. Jamieson, G. F. Tyers et al., "Primary cardiac tumors: experience with 25 cases," The Journal of Thoracic and Cardiovascular Surgery, vol. 83, pp. 339-348, 1982.

[6] K. P. Abraham, V. Reddy, and P. Gattuso, "Neoplasms metastatic to the heart: review of 3314 consecutive autopsies," The American Journal of Cardiovascular Pathology, vol. 3, pp. 195-198, 1990.
[7] J. McAllister H.A., R. J. Hall, and D. A. Cooley, "Tumors of the heart and pericardium," Current Problems in Cardiology, vol. 24, no. 2, pp. 63-116, 1999.

[8] N. A. Silverman, "Primary cardiac tumors," Annals of Surgery, vol. 191, no. 2, pp. 127-138, 1980.

[9] A. Habertheuer, M. Ehrlich, D. Wiedemann, B. Mora, C. Rath, and A. Kocher, "A rare case of primary cardiac B cell lymphoma," Journal of Cardiothoracic Surgery, vol. 9, no. 1, article no. 14, 2014.

[10] S. Y. Min, Y.-H. Lim, H. T. Lee, J. Shin, K.-S. Kim, and H. Kim, "Biatrial myxoma and multiple organ infarctions combined with Leriche syndrome in a female patient," BMC Cardiovascular Disorders, vol. 14, no. 1, article no. 175, 2014.

[11] U. Reiter, G. Reiter, M. Asslaber et al., "Characterization of a calcified intra-cardiac pseudocyst of the mitral valve by magnetic resonance imaging including T1 and T2 mapping," BMC Cardiovascular Disorders, vol. 14, article no. 11, 2014.

[12] K. D. Horn, M. J. Becich, R. Y. Rhee, and S. M. Pham, "Left atrial myxoma with embolization presenting as an acute infrarenal aortic occlusion," Journal of Vascular Surgery, vol. 26, no. 2, pp. 341-345, 1997.

[13] K. Reynen, "Medical progress: Cardiac myxomas," The New England Journal of Medicine, vol. 333, no. 24, pp. 1610-1617, 1995.

[14] L. Simpson, S. K. Kumar, S. H. Okuno et al., "Malignant primary cardiac tumors: review of a single institution experience," Cancer, vol. 112, no. 11, pp. 2440-2446, 2008.

[15] P. J. Leedman, A. K. Cohen, and L. R. Matz, "The complex of myxomas, spotty pigmentation and endocrine overactivity," Clinical Endocrinology, vol. 25, no. 5, pp. 527-534, 1986.

[16] C. M. Steger, T. Hager, and E. Ruttmann, "Primary cardiac tumours: a single-center 41-year experience," ISRN Cardiology, vol. 2012, Article ID 906109, 7 pages, 2012.

[17] A. W. Elbardissi, J. A. Dearani, R. C. Daly et al., "Survival after resection of primary cardiac tumors: a 48-year experience.," Circulation, vol. 118, no. 14, pp. S7-15, 2008.

[18] M. Khan, P. Sanki, M. Hossain, A. Charles, S. Bhattacharya, and U. Sarkar, "Cardiac myxoma: A surgical experience of 38 patients over 9 years, at SSKM hospital Kolkata, India," South Asian Journal of Cancer, vol. 2, no. 2, pp. 83-86, 2013. 


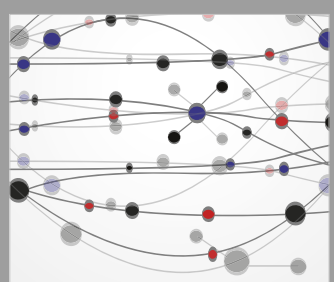

The Scientific World Journal
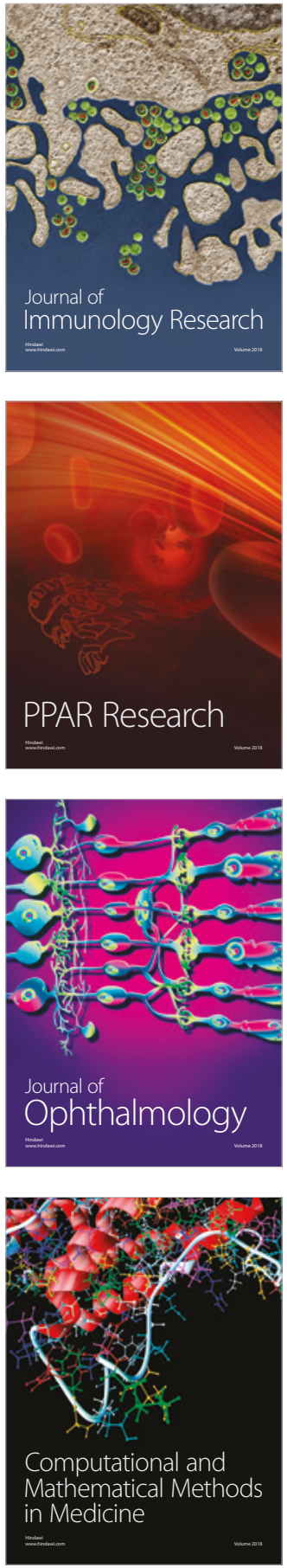

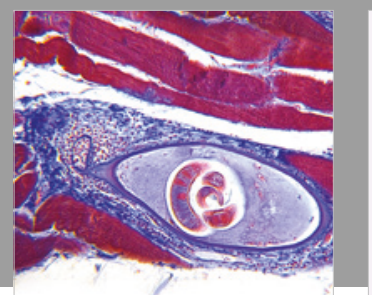

Gastroenterology Research and Practice

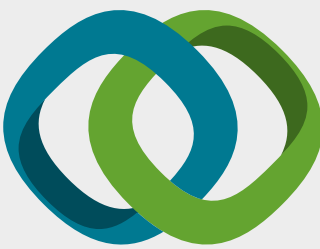

\section{Hindawi}

Submit your manuscripts at

www.hindawi.com
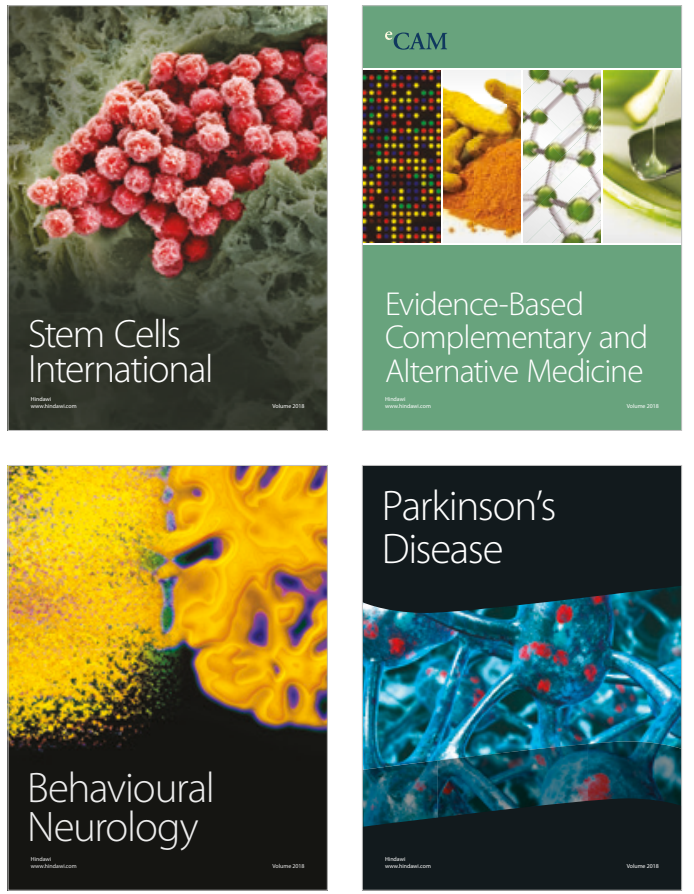

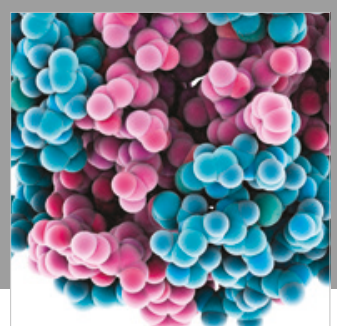

ournal of

Diabetes Research

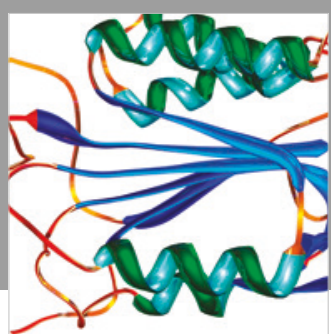

Disease Markers
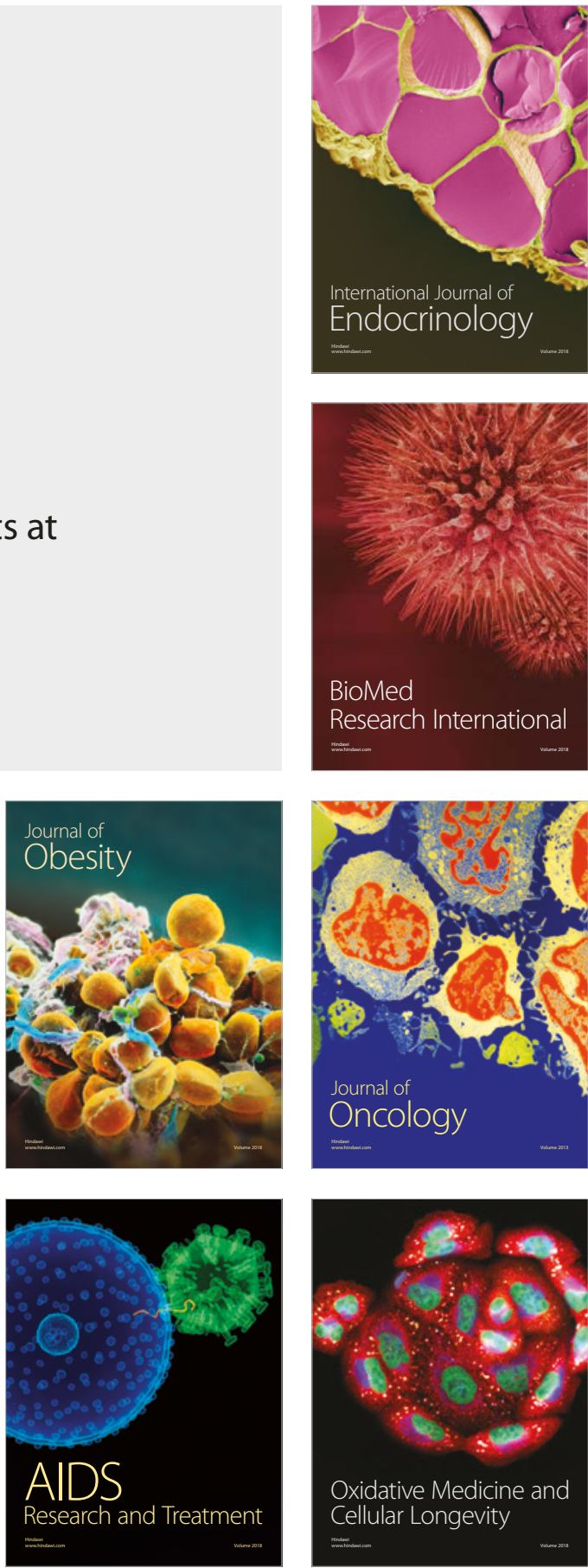